\title{
Infusing Computational Thinking in an Integrated STEM Curriculum: User Reactions and Lessons Learned
}

\author{
Dazhi Yang ${ }^{1 *}$, Youngkyun Baek ${ }^{1}$, Yu-Hui Ching ${ }^{1}$, Steve Swanson ${ }^{1}$, Bhaskar Chittoori ${ }^{1}$, Sasha Wang ${ }^{1}$ \\ ${ }^{1}$ Boise State University, USA
}

*Corresponding Author: dazhiyang@boisestate.edu

Citation: Yang, D., Baek, Y., Ching, Y.-H., Swanson, S., Chittoori, B., \& Wang, S. (2021). Infusing Computational Thinking in an Integrated STEM Curriculum: User Reactions and Lessons Learned. European Journal of STEM Education, 6(1), 04. https://doi.org/10.20897/ejsteme/9560

Published: January 15, 2021

\begin{abstract}
This study describes the design and implementation of an integrated STEM + computational thinking (CT) curriculum, which was guided by project-based learning, for integrating CT in after-school programs. The study examined teachers and students' reactions to the curriculum and the challenges in implementing such a curriculum. Results show that most students and teachers reacted positively toward the curriculum. Main challenges to implementing such a curriculum were also identified. Lessons learned from the curriculum implementation are discussed. The study contributes to the integration of CT and development of CT in students. It also contributes to teacher professional development regarding CT integration.
\end{abstract}

Keywords: computational thinking (CT), integration of CT, integrated STEM, curriculum design, projectbased learning (PBL), after-school programs

\section{INTRODUCTION}

\section{What is Computational Thinking and Why is it Important?}

Computational thinking (CT) is a fundamental skill that involves problem formulation, problem-solving, and scientific reasoning (Wing, 2006). CT is also a metacognitive process that involves sub-skills and dispositions for regulating complex problem-solving and modeling unobservable phenomena (Dwyer et al., 2014). Therefore, CT is considered the "third pillar" of scientific practice (PITAC, 2005) and is a fundamental $21^{\text {st }}$ century skill (PCAST, 2010).

The integration of CT in K-12 for science, technology, engineering and mathematics (STEM) learning has the potential to improve science learning and increase student engagement in STEM learning via CT-embedded scientific inquiry (Yang et al., 2018). Integrating CT into the classroom helps prepare students for the future by encouraging creativity and problem solving (Fessakis et al., 2013). Although researchers have studied K-12 student mathematical thinking and scientific reasoning extensively (Bicer et al., 2015), the development of CT in K-12 students has received much less attention (Lye \& Koh, 2014). The practice of CT in K-12 STEM learning is rarely studied (Sengupta et al., 2018). Moreover, currently CT is widely missing in K-12 STEM education (NRC, 2011). The question that researchers and educators in STEM education are facing is not why we need to integrate CT, but how. Therefore, it is critical to examine productive ways to integrate CT in K-12 STEM education. 


\section{LITERATURE REVIEW}

CT is relatively new for many K-12 researchers and educators. However, the fundamental skills emphasized in CT are vital for STEM learning because of their relationship with the STEM disciplinary processes of modeling, reasoning, and problem solving (Sengupta et al., 2013). The STEM subjects also provide a natural context for CT learning (Grover \& Pea, 2018). The Next Generation Science Standards (NGSS) recognized CT as a key scientific practice (NGSS Lead States, 2013), which has prompted various attempts to integrate CT into K-12 classrooms based on limited research (Stanton et al., 2017). Moreover, the National Science Board (2010) has also supported teaching CT in K-12 education. In addition, the review of CT integration in several European countries and the United States has shown that including "CT aspects in the curriculum is relevant in all countries" (Mannila et al., 2014, p. 9).

\section{Integrating CT in K-12 Education}

Recent attempts to integrate CT into K-12 education fall into three categories: a) the stand-alone addition of programming activities that support little to no subject content learning (Lye \& Koh, 2014); b) integration that supports subject content learning "as ways to describe, make comparisons between, and test predictions about systems" in problem-solving (Wilkerson \& Fenwick, 2016, p. 186); and c) integration aligned with the practice of STEM professionals showing students how professionals practice CT (Winthrop et al., 2016). Although different CT integration approaches have been reported (Israel et al., 2015), researchers generally agree that instructional support should be offered during the process (Sengupta et al., 2013).

Coding and programing activities are some of the popular integration approaches at the K-12 level. Scratch, a visual programming language, has been integrated into many classroom instructional activities to teach computing and programing to lower level elementary students, whereas Java or Python may be used to develop programming skills in older students (Israel et al., 2015). Research indicates that the integration of visual programming languages in K-12 classrooms can improve students' CT and computational practices (e.g., experimentation and iteration). However, the use of programming as the learning context in CT integration has led to the confusion that CT equates with programming, or that CT practice has to at least involve programming (Voogt et al., 2015).

More recent CT integration has focused supporting subject content learning, which is reflected in the view of CT as a necessary transdisciplinary skill (Wing, 2008). In practice, some science educators have had students focus on an ecosystem using CT to conduct experiments, whereas others have advocated the use of modeling physical phenomena to teach CT. Students can also be exposed to the work of STEM professionals which can help them apply CT skills, reflecting another view of CT that considers the human experience and creativity in CT integration (Wing, 2008).

Most previous CT integration in K-12 education has shown that CT was embedded in only one or two subject areas. More recently, researchers have adopted an integrated STEM education approach to solve problems (Yang et al., 2018). At the same time, in order to train teachers, researchers have started to include teacher professional development (PD) in their approach toward integrating CT in K-12 science inquiry (Elby et al., 2015). However, most teacher PD does not immerse teachers and students together in inquiry experiences (Wilson, 2013). As a result, critical teacher-student interactions are missing, which runs counter to the strengths of inquiry-based learning (Linn \& Hsi, 2000).

Research indicates that CT can be effectively integrated into K-12 STEM education and inquiry (NRC, 2011). Most pedagogical approaches, such as problem-based hands-on inquiry, trial and error within science experiments, and guided arguments, are all used to integrate CT into K-12 education, and have been recommended for formal learning environments (NRC, 2011). However, these pedagogies can also be adopted in informal ones. In fact, running structured STEM projects in informal settings can provide a suitable learning environment to explore the integration of CT in STEM disciplines because both teachers and students have the time and opportunity for thoughtful and reflective engagement in complex projects (NRC, 2011).

\section{After-School vs. In-School Programs}

Formal (in-school) programs are structured and planned curriculum activities that are led and facilitated by trained personnel while informal (after-school) programs are less structured activities that often have no predesigned learning objectives (Czerkawski \& Hernandez, 2011). The systematical structure with pre-designed learning objectives of formal curricula entails the quality and complete coverage of subject content. The facilitation of the formal curricula by well- trained instructors is also a major advantage compared with that of the informal programs and curricula. Thus students can be expected to systematically learn and master fundamental subject content mapped to well established content standards with formal programs and curricula. However, all stakeholders including students, teachers, as well as industries have called for the reforms in formal curricula for 
the lack of changes accompanying the advances of the society (Stocklmayer et al., 2010). For example, the reform within a formal curriculum such as the implementation of a student-centered learning approach like the projectbased learning for real world problem solving has always been challenging and faced with resistance (Marx et al., 1997). One reason for such challenge and resistance lies in the teachers' lack of time and expertise to explore innovative practice to implement the needed changes within a formal curriculum (Stocklmayer et al., 2010). The challenge in providing students with relevant problem solving and learning activities often results in an outdated curriculum that fails in equipping a workforce with desired skills.

Informal programs and curricula are highly adaptable and are an ideal context for bridging both formal and informal programs for STEM learning (Braund \& Resiss, 2007; Fallik et al., 2013) while offering a semi-structured environment for hands-on, immersive, and authentic learning to occur. For an informal program and curriculum, its loose structure without pre-designed learning objectives nor the mandate for meeting the standard testing allows both teachers and students to explore a topic in a more relaxed way (Linn \& Hsi, 2000). Thus informal programs and curricula provide an ideal learning context for experimenting interventions and innovative practice (Braund \& Resiss, 2006). Researchers and practitioners are increasingly focusing on bridging informal and formal programs as both have advantages and disadvantages (Braund \& Resiss, 2006; Fallik et al., 2013). Eshach (2007) suggested that bridging formal and informal curricula can be achieved by recognizing the advantages and disadvantages of both curricula and implementing the desired learning experience accordingly.

In after-school venues, students have the time to engage in complex projects that are better suited to nurturing CT than during the narrow windows of opportunity in formal settings. An after-school program is well suited to integrate CT in STEM learning, allowing students and teachers to work as partners so that everyone is learning collaboratively (Linn \& Hsi, 2000). Community centers are particularly well-suited to informal learning as they offer a setting in which learning activities are typically expected over a sustained period of time. After-school settings also give teachers the freedom to experiment and not worry about class time being taken away. Additionally, there are too few K-12 students who are exposed to CT in non-school programs (PCAST, 2010). Thus, an informal, after-school setting could be the most appropriate, as well as needed for implementing a complex curriculum integrated with CT.

\section{Productive CT Integration Environments}

Productive CT integration lies in the design of the integration, whether it be the design of an activity, a lesson, or curriculum. As discussed in the NRC's (2011) report, most students find it highly motivating to work in teams with teachers and peers on a project, and students often develop the ability to communicate concepts with others, share resources, and develop the products with their peers. Therefore, the appropriate environment for integrating CT should support social interactions, cooperation, and collaboration (Chowdhury et al., 2018).

Project-based learning (PBL) is a constructivist instructional method that engages students in constructing knowledge and learning skills with teachers and their peers through "an extended inquiry process structured around complex, authentic" questions (BIE, 2017, para. 4). The PBL approach is also consistent with best practices for STEM learning such as providing students with opportunities that are authentic (i.e., participating in "real" science), inquiry-based, relevant to them as learners, and supportive and collaborative (NRC, 2005). PBL can guide the design and development of a productive learning environment and curriculum in terms of delivering the content and fostering the development of CT in elementary students with social interaction, teacher scaffolding, and handson activities in STEM learning. The PBL approach enables the design of hands-on activities that allow students to investigate relevant topics or problems and to learn through the active creation of final products. In PBL, all learning activities and objectives are driven by an overall guiding question. At the end of a unit, students showcase their final products, often through a competition or an exhibition.

Previous research has shown the advantage of engaging students in an integrated STEM learning environment that requires the application of multiple STEM concepts and skills as opposed to focusing on discrete subject areas (Wang et al., 2011). Teachers also benefit from such an integrated learning environment since it can serve to complement and even reinforce their existing curriculum. By designing inquiry environments in which CT is integrated with multiple STEM topics, teachers are less likely to feel that they are pulling time or materials away from other subjects, and by contrast they are helping solidify student learning comprehensively. Therefore, an integrated STEM+CT learning environment guided by PBL inquiry, which requires students to learn, explore, and apply more than one discipline to solve problems, would be productive for integrating CT for K-12 students. This is consistent with the claim that for K-12 students to develop CT literacy and competency, they must gain not only CT skills, but also a deeper knowledge of where CT is relevant, including disciplinary practice (Grover \& Pea, 2018). 


\section{METHODS}

\section{Purpose of the Study}

This study presents the design and development of a project-based STEM+CT curriculum for integrating CT in an after-school program as a backdrop and subsequently explores the users' (teachers and students) reactions to the curriculum. Two research questions were formed: How would teachers and students react to (think and feel about) the project-based integrated STEM+CT curriculum in an after-school setting? What would the challenges be when implementing such a STEM +CT curriculum in an after-school setting?

\section{The PBL Guided STEM+CT Curriculum}

The curriculum design team consisted of a group of interdisciplinary faculty members in educational technology, mathematics education, engineering, and a former NASA astronaut, as well as a school district STEM content supervisor.

The STEM+CT curriculum consisted of several PBL projects, which with a project topic and overview, a driving question and sub-questions, learning objectives and outcomes, student activities, and required resources. The driving question and sub-questions helped guide the learning process and hands-on inquiry. Content wise, the STEM+CT curriculum projects were designed for upper elementary ( $4^{\text {th }}$ to $6^{\text {th }}$ ) grade levels since those students are developing abstract thinking (Inhelder \& Piaget, 1958).

Table 1 illustrates two STEM+CT project-based projects. One is Life on Mars and the other is the Bridge Design. The Life or Mars and Bridge Design topics were chosen because both were relatively easy to integrate with different STEM subject content, were motivating (such as learning about Mars), or related to students' physical surroundings like building a bridge for a river in the students' local community, an active earthquake area. Both projects lasted eight-weeks and required students to integrate STEM subjects with CT to solve the overall driving question. The following table lists the essential components of each project in the form of the PBL-guided inquiry.

Table 1. STEM+CT Projects Guided by PBL

\begin{tabular}{lll}
\hline Projects & Life on Mars & Bridge Design \\
\hline Description & $\begin{array}{l}\text { Students research different forms of life and the } \\
\text { Martian environment, design and assemble a robot to } \\
\text { detect life on a simulated Mars. }\end{array}$ & $\begin{array}{l}\text { Students research earthquakes and bridges, design an } \\
\text { earthquake resistant bridge, and build and test their } \\
\text { bridges under simulated earthquake conditions. }\end{array}$ \\
\hline Outline & $\begin{array}{l}\text { Week 1 to 4: Research forms of life and Mars; assemble } \\
\text { a robot; learn to program; } \\
\text { Week 5 to 8: Assemble, program, and test a robot; final } 1 \text { to 4: Research earthquakes and bridges; } \\
\text { competition }\end{array}$ & $\begin{array}{l}\text { Week 5 to 8: Design, build, and test a bridge; final } \\
\text { competition }\end{array}$ \\
\hline Learning Objectives & $\begin{array}{l}\text { Students investigate life on Mars and how it can be } \\
\text { detected; design and build a robot to detect life on } \\
\text { Mars. }\end{array}$ & $\begin{array}{l}\text { Students investigate bridges and earthquakes; design } \\
\text { and build a bridge and test it under simulated } \\
\text { earthquake conditions. }\end{array}$ \\
\hline Driving Question & How can we detect life on Mars using a robot? & $\begin{array}{l}\text { How can we build a strong bridge for the Mountain } \\
\text { River to resist earthquake forces? }\end{array}$ \\
\hline Final Product & An assembled/programmed robot & A bridge built with specified criteria \\
\hline Sample Hands-on & Assembling and programming a robot & Designing, building and testing a bridge \\
Activities & & $\begin{array}{l}\text { Final competition on which bridge is the strongest in } \\
\text { resisting earthquake forces. }\end{array}$ \\
\hline Assessment & $\begin{array}{l}\text { Final competition in which robot detects life in the } \\
\text { shortest time. }\end{array}$ & K'Nex building kits; Laptops; etc. \\
\hline Resources Needed & Mindstorms LEGO (EV3) set; Laptops; etc. &
\end{tabular}

The STEM+CT projects also included final learning outcomes, student activities, assessment, and required resources (Table 1). Both projects were designed for small groups of four to six students based on the sharing of project materials such as Lego Mindstorms kits, as well as the project tasks and available time. Both projects covered multiple STEM subjects and provided learning objectives based on the guiding question and its subquestions. The overall driving questions were: How can we detect life on Mars using a robot? and How can we build a bridge for the Mountain (pseudonym) River that is strong enough to resist earthquake forces?

\section{Learning Activities}

The Life on Mars project was designed to engage students to practice and apply CT and integrate science, math, engineering, computer science, and technology through robotics and programming. Scientific knowledge and concepts (e.g., forms of life, the planet Mars) and robotics and programming concepts were introduced in the first four weeks. Students assembled robots using Lego Mindstorms kits and programmed the robots with Mindstorms EV3 software. The purpose of programming the robot was to find "water" (a green dot) on a surface that simulated 

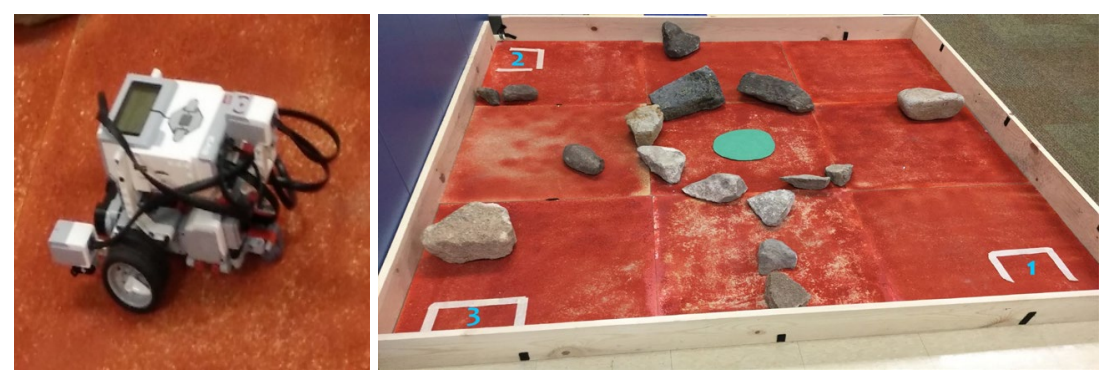

Figure 1. Assembled and programmed robot and simulated Mars

Mars, since water is most likely where life would be found. Figure 1 shows a robot that was assembled and programmed by students.

The CT integration in this project was beyond the stand-alone addition of programming or coding. It supported students' learning of STEM concepts related to the Martian environment in order to solve the problem of how to use a robot to detect life on Mars. At the start of the fifth week, students assembled and programed robots, which were showcased in week eight in a race to detect life (the green dot in Figure 1). The team that found "life" in the shortest amount of time, won.

The Bridge Design project was designed to have students apply CT and integrate STEM through engineering design and bridge building. At the core of the engineering design process were: defining and identifying a problem; developing possible solutions; designing and testing prototypes; and making revisions (Chabalengula \& Mumba, 2017). In this project, scientific knowledge and engineering concepts (e.g., earthquakes, bridges) were introduced in the first four weeks. Engineering design concepts (e.g., developing possible solutions and building prototypes) were introduced in later weeks while students were designing and building bridges. Starting in the fifth week, students built an earthquake-resistant bridge with K'Nex kits and prepared for a final competition. Each of the K'Nex pieces had an associated price tag, which the students used to keep track of bridge costs for the final competition. In the eighth week, students competed for the best bridge design judged by design specifications (width of at least 2 feet, height of at least 1.5 feet, having two towers, and meeting the pre-determined earthquake testing criteria) plus the cost.

\section{Embedded with $C T$}

To facilitate the integration of CT, the research team highlighted some CT components for student hands-on inquiry and problem-solving based on an extended review of literature (e.g., Brennan \& Resnick, 2012; Grover \& Pea, 2013, 2018). Subsequently, 11 CT components displayed in Table 2 were embedded in both projects based on our curriculum's learning objectives and activities (see Table 1).

The STEM+CT curriculum focused on students' ability (e.g., practices) to solve problems using CT (Grover \& Pea, 2018). The vocabulary and terminology (Table 2) focuses on student computational literacy and the use of appropriate CT terminology while communicating their thoughts and actions during scientific inquiry. CT vocabulary and terminology usage can overlap with math and science in a STEM $+\mathrm{C}$ learning environment. The majority of the CT components focuses on student ability to form and communicate problems (Grover \& Pea, 2018) as well as solve problems (Wing, 2006). Specifically, abstraction, algorithms, conditional logic, data structures, analysis and representation, decomposition, and heuristics focus on the thought process and logic in problem solving. CT components of data collection, data structures, analysis and representation, pattern recognition, and simulation and modeling focus on students communicating and dissecting problems while creating and generating different questions, as well as resolving those questions. Communication focuses on both oral and written descriptions of student inquiries, usually supported by visuals, graphics, or simulations. Since the PBL approach emphasizes the importance of providing reflection and students voices, communication is one of the CT components highlighted and embedded throughout the curriculum design. Table 2 also includes some curricular examples of each embedded CT components.

The following screen capture is an example of how CT components were embedded in student inquiry activities.

As shown in Figure 2, students collected data about Mars' environment via watching videos and reading websites (e.g., What Is Mars? by NASA) that were selected by the researchers. Students were also guided by questions during data collection and took notes about their findings. In one part of the curriculum, students worked independently and in groups of two to three in collecting data on Mars' environment. Students' data collection in this project involved gathering and obtaining data, and more importantly organizing them in the form of drawings or student-produced graphics. This organization was to identify the key characteristics and patterns of the data to answer a research question such as what the environment of Mars looks like. Finally, students presented their findings, along with the data they collected, to their peers (CT communication). The presentations were also 
Table 2. CT Embedded in the STEM+CT Curriculum

\begin{tabular}{|c|c|c|}
\hline CT Component & Description & Example of Embedded CT \\
\hline CT vocabulary & $\begin{array}{l}\text { Variables, data, modeling, testing and debugging, iterative, } \\
\text { etc. (Brennan \& Resnick, 2012; Lye \& Koh, 2014) }\end{array}$ & Test, analyze, debug, retest, so \\
\hline Abstraction & $\begin{array}{l}\text { Reducing complexity and generalizing from specific } \\
\text { instances to make sense of things (An \& Lee, 2014; Lee et } \\
\text { al., 2011) }\end{array}$ & Identifying each of the characteristics of strong bridges \\
\hline Algorithm & $\begin{array}{l}\text { Applying specific set of tools or sequence of steps } \\
\text { (processes) to solve problems (Yadav, Zhou, Mayfield, } \\
\text { Hambrusch, \& Korb, 2011) }\end{array}$ & $\begin{array}{l}\text { Programming the Lego Mindstorms EV3's software } \\
\text { blocks, testing and repeating until a task is competed }\end{array}$ \\
\hline Communication & $\begin{array}{l}\text { Written and oral descriptions supported by graphs, } \\
\text { visualizations, etc. (Astrachan \& Briggs, 2012) }\end{array}$ & $\begin{array}{l}\text { Presenting research finding via Google slides or other } \\
\text { visuals }\end{array}$ \\
\hline 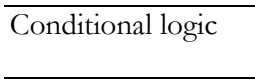 & $\begin{array}{l}\text { Using strategy such as an "if-then-else" construct to } \\
\text { clarify problems and solutions (Wing, 2006) }\end{array}$ & Programming a robot using the if- then command/block \\
\hline Data collection & $\begin{array}{l}\text { Gathering data to define or solve a problem (Grover \& } \\
\text { Pea, 2013) }\end{array}$ & $\begin{array}{l}\text { Gathering and analyzing the simulated Mars area to } \\
\text { determine what path the robot should take }\end{array}$ \\
\hline $\begin{array}{l}\text { Data structures, } \\
\text { analysis and } \\
\text { representation }\end{array}$ & $\begin{array}{l}\text { Exploring data to find patterns, causes, trends, or results } \\
\text { to facilitate the knowledge construction and problem } \\
\text { solving (Grover \& Pea, 2013; CSTA, 2009) }\end{array}$ & $\begin{array}{l}\text { Using distance and speed to determine the time a robot } \\
\text { should move in a specific direction }\end{array}$ \\
\hline Decomposition & $\begin{array}{l}\text { Simplifying problems or specifying steps to solve } \\
\text { problems (Catlin \& Woollard, 2014) }\end{array}$ & $\begin{array}{l}\text { Determining which Lego Mindstorms EV3's software } \\
\text { blocks are needed for a robot to turn left or right, then } \\
\text { programming the blocks, testing and repeating until the } \\
\text { task is competed }\end{array}$ \\
\hline Heuristics & $\begin{array}{l}\text { Applying experience-based strategy that facilitates } \\
\text { problem solving (Yadav et al., 2011) }\end{array}$ & $\begin{array}{l}\text { Using the trial and error strategy while programming and } \\
\text { testing }\end{array}$ \\
\hline Pattern recognition & $\begin{array}{l}\text { Recognizing repeated patterns such as iteration or } \\
\text { recursion (Grover \& Pea 2013, 2018) }\end{array}$ & $\begin{array}{l}\text { Identifying the same characteristics of strong bridges } \\
\text { from the data collected from different sources }\end{array}$ \\
\hline $\begin{array}{l}\text { Simulation and } \\
\text { modeling }\end{array}$ & $\begin{array}{l}\text { Manipulating data or concepts through controlled } \\
\text { programs or exercises or creating such programs for data } \\
\text { manipulations (CSTA, 2009) }\end{array}$ & $\begin{array}{l}\text { Using an online program to simulate the strength of a } \\
\text { bridge while varying the values of the input variables }\end{array}$ \\
\hline
\end{tabular}

\section{CT component embedded in student activities:}

- Data collection: Student collect data on the environment of Mars.

- Abstraction: Students identify main characteristics of the environment of Mars.

- Communication: Students present their findings on the environment of Mars.

Figure 2. Embedded CT components in the Life on Mars project

followed by a discussion to reach a consensus on the common key characteristics of the Mars' environment. Students applied the CT components of data collection, data structure, abstraction and communication to answer the research questions in the STEM+CT curriculum. In these activities, CT components of data collection, data structures, analysis and representation as well as CT communication were embedded through the curriculum design.

Another example of embedded CT in the curriculum is student practice of CT in problem solving. For example, students had to translate the measurements of distance or degrees into input values while programming a robot to go forward or to turn left or right. At the same time, the students had to interpret a physical action of a robot into programming languages such as using the if- then command, which helped students develop CT skills and logical thinking. The integrated STEM+CT curriculum provides student a learning context which was quite different than what they usually practiced in the classrooms. The integration of CT and the design of the curriculum, such as the built-in guiding questions and relevant resources for answering them, also supported student learning of science and problem solving. Descriptions of CT and more examples of embedded CT components in the curriculum can be found in Table 2 . The examples of student practice of CT are centered on problem solving and engineering design activities.

\section{Implementing the STEM+CT Curriculum}

The implementation of the STEM+CT curriculum was led by in-service teachers working with small groups of students in community centers' after-school programs over eight weeks (two 90-minute sessions per week) for a total of 16 sessions. All STEM+CT curriculum materials were available via a Google site and shared with all teachers prior to the implementation.

The curriculum was implemented at two community centers' after-school programs. The community centers helped recruit $184^{\text {th }}$ to $6^{\text {th }}$ grade students for each of the projects on a first come, first served basis and a total of 36 students participated. The community centers were adjacent to a Title I (at least $45 \%$ of its students receive free 
or reduced lunches) elementary school. The community centers' staff escorted the students to the classrooms of their Title I schools where the project team and teachers would meet around 3:40 pm on the project days (Mondays/Wednesdays or Tuesdays/Thursdays).

\section{Implementation Led by Teachers}

The research team worked with the local school district, which helped recruit six teachers (three per project per location) to facilitate the implementation of two STEM+CT projects. Two weeks prior to implementing the projects at the community centers, the research team led two, three-hour PD sessions on CT, PBL, and the subject content of each project. In addition, a brief preview of the project's weekly sessions was provided. The teachers were directed to facilitate and guide the students during the implementation of the curriculum. The teachers assumed various roles such as a helper, motivator, facilitator, resources provider, co-learner, and a problem-solving guide. The teachers received a stipend, as well as two PD credits, from the researchers' institute for their participation and facilitation of the project. At least two researchers of the curriculum design team were present at each location during the eight-week period to facilitate them.

\section{Data Collection and Analysis}

Teachers were asked to write a weekly reflection after leading two sessions. The teachers were provided with specific prompts to guide their reflections and solicit their experience with the curriculum, students' reactions to it, and implementation challenges. The reflection prompts varied slightly from week 1 to week 8 as the project progressed but all six teachers in both projects had the same prompts. Each teacher's weekly reflection ranged from half to one and a half pages (single-spaced) with an average of 266 words.

Student focus group interviews were conducted at the end of the implementation to examine their reactions. Four focus group interviews (one interview with 3 students for the Life on Mars project and three interviews with 12 students for the Bridge Design project) were conducted. 14 students (11 boys and four girls) participated in four focus groups. Table 3 presents an overview of the participants as well as the data sources.

Table 3. Participants and Data Sources

\begin{tabular}{|c|c|c|c|c|c|c|}
\hline \multirow{2}{*}{ Participants } & \multicolumn{2}{|c|}{ Projects } & \multirow[b]{2}{*}{ Total } & \multicolumn{2}{|c|}{ Data Sources } & \multirow[b]{2}{*}{ Total } \\
\hline & Life on Mars & Bridge Design & & Life on Mars & Bridge Design & \\
\hline Teachers & 3 & 3 & 6 & Weekly Reflection (19) & Weekly Reflection (20) & 39 \\
\hline Students & 18 & 18 & 36 & Focus Group (1) & Focus Group (3) & 4 \\
\hline
\end{tabular}

The focus group interviews were transcribed and prepared for analysis in Nvivo by one graduate research assistant. Teachers' reflections were imported into Excel for data analysis by another graduate research assistant. The two graduate research assistants then conducted a thematic analysis to examine the teacher reflections and student focus group interviews for themes by "identifying, analyzing and reporting patterns within data" (Braun \& Clarke, 2006, p. 79) independently. The data analysis was then reviewed and roughly $30 \%$ of the reflections and interviews were analyzed by a faculty researcher. An inter-rater reliability of $96 \%$ based on the shared coding for the reflections, and a similar inter-rater reliability of $88 \%$ for the interviews were found, which were higher than the minimum acceptable threshold of 75\% (Graham et al., 2012).

\section{RESULTS}

\section{Student Practice of CT}

Before presenting the research findings, we would like to share two examples of student work and student reasoning to further illustrate student practice of CT components, which aims to serve as a backdrop for understanding the teachers and students reactions to the curriculum as well as lessons learned from the curriculum design and implementation. The first example is a screenshot of a student's codes for programming the robot to follow a path leading to the "life" on a simulated Mars. In this example, students had to use or practice various CT components such as conditional logic (the if-then command) and heuristics (trial and error and debugging) to accomplish the task. 


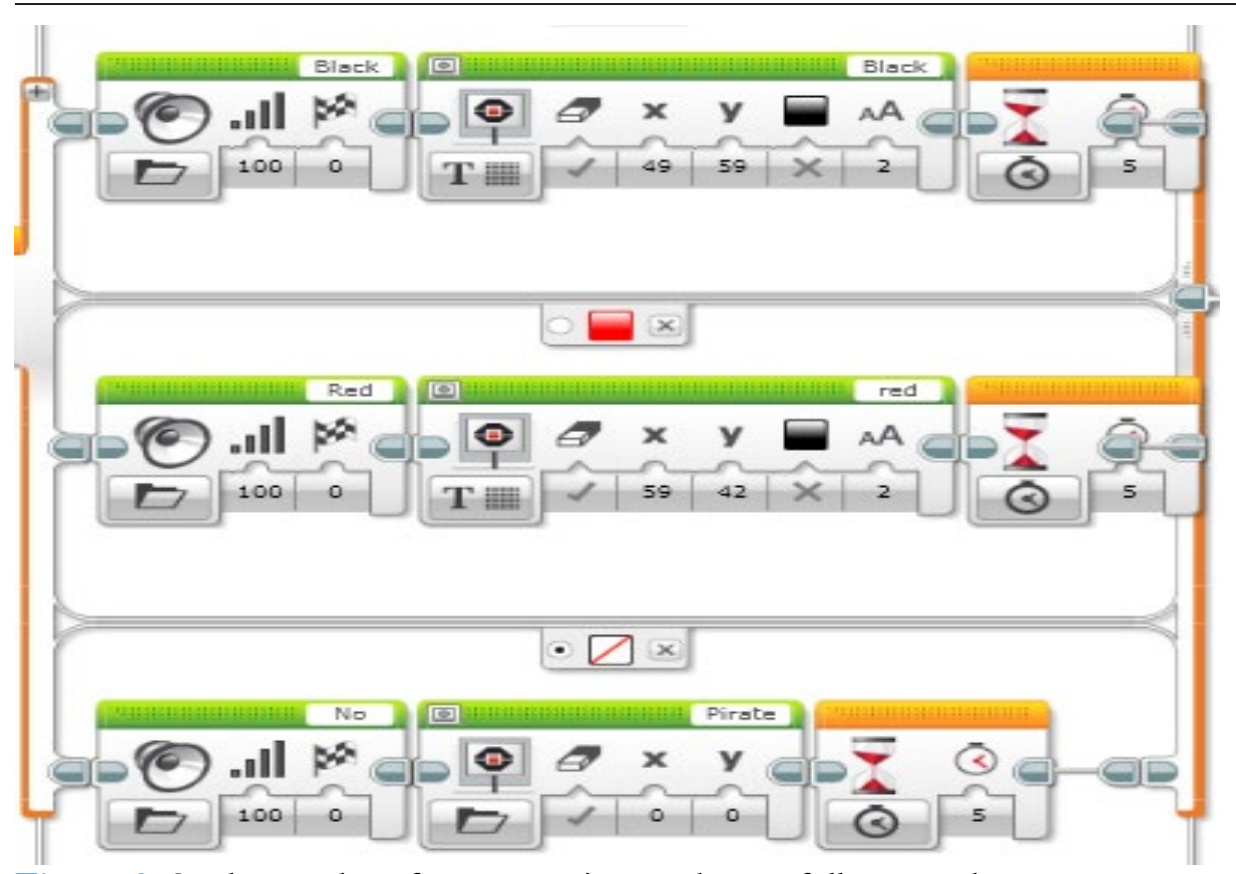

Figure 3. Student codes of programming a robot to follow a path

The second example provides a small vignette of student reasoning that took place during the discourse of problem solving. A student was testing his robot and seemed frustrated that it was not working after trying the same approach several times. A facilitator stepped in to find out what was going on and had the following conversation.

Facilitator: Okay, so read the problem. So, you're making the robot move straight at a speed of 60. That was... it's doing right there?

Student: I'm gonna put a speed of 100.

Facilitator: Now, what's the problem? Is it 60 or 100 ?

Student: 100.

Facilitator: No.

Student: I want it to be 100 because ...I'll know myself.

Even though this student was not following the written instructions to make the robot move at a speed of 60 , he persisted in trying his own value and engaged in thinking on his own. The student had to reason abstractly and quantitatively while interpreting the physical action of a robot and translating the measurements of speed into programming. The trial-and-error approach gave him the space to test his own reasoning. More student work and artifacts demonstrating CT practice can be found in our recent report on elementary school students' CT practice in a bridge design challenge (Yang et al., 2019).

\section{Teachers' Reactions to the Curriculum}

Teachers in the Life on Mars project reflected that they mostly had positive experiences. For example, one teacher wrote, "I was also impressed by the students. ... It was great to see that some students had background knowledge on either life or robots. I loved seeing most of them excited and eager to get started on the project. The collaboration, discussion, and work ethic made me proud to be a teacher at their school." The teachers liked that all of the curriculum materials were online and readily accessible. For example, one teacher wrote, "It helped ... with the links [of the curriculum materials] readily available. It made transitions much smoother."

In the Bridge Design project, the teachers reported that students were more interested in doing the hands-on activities, rather than reading and researching. One teacher observed, "Students are coming from a full day of learning (reading, writing, researching) at school and they want to participate in hands-on activities and have a REALLY hard time engaging in reading, researching and notetaking." The teachers also recognized acquiring foundational knowledge through researching was important for students to design and build an earthquake-resistant bridge. Due to students' low interest in research, a couple teachers proposed using videos instead texts. One teacher wrote "... if students have to do research, then videos would be more engaging for students than reading heavy with words."

In the Life on Mars project, all three teachers described the beneficial outcome of their participation in the project from different perspectives. One teacher emphasized that she gained more confidence in teaching STEM concepts as a result of her participation. Another teacher stated that the project broadened her horizon on how much technology could be used in facilitating STEM teaching and learning. The third teacher would like to add 
more STEM activities and facilitate them in her classroom. In the Bridge Design project, all three teachers reflected that they would incorporate similar hands-on activities in their own classrooms. One teacher wrote, "This experience enbanced my skills in STEM and CT. I will bring this teaching experience to my third grade classroom. I learned a lot and [my learning] will transfer to many areas."

\section{Students' Reaction toward the Curriculum}

In the Life on Mars project, all three teachers reflected that students were very excited and engaged in the activities, especially the robot activities. One teacher pointed out that the introduction of the driving question (see Table 1) had helped students realize the importance of having background knowledge before they conducted hands-on activities.

In the Bridge Design project, the teachers reported that students were not fully engaged in the discussions and readings in the first session. One teacher provided a possible reason for the students" low engagement as "Session 1 was incredibly rushed, as there was no time allowed in the lesson plans to meet/greet the new students and then the rest of the readings and discussions were rushed." However, all teachers pointed out that the students were more engaged in conversations among themselves and enjoyed exploring different types of bridges in the second session.

In the Life on Mars project, students expressed positive reactions through an interconnected set of themes ranging from coding, building robots, learning about Mars, making new friends, working in teams, and having fun in the focus group interview. Even when students' efforts did not go according to plan, they still had fun participating in the activities as one student said "I also liked the obstacle course we had to run through, even though we failed." Another student appreciated the experience of learning how to code, "I didn't know how to code before and I got to try something new." Another expressed that what they (their peers) enjoyed most "was learning how to use programming and making a robot move and sense things." In the Bridge Design project, students similarly expressed having fun, enjoying the hands-on activities, and making new friends. Students described their experience as "It's just fun playing with the K'NEX kit and building something with it." All the students who were interviewed expressed that they had fun and hoped that they would be able to participate in similar projects again in the future.

In the Life on Mars project, students expressed frustrations with insufficient time in the sessions and noted how, consequently, they felt being rushed in the focus group interviews. One student stated, "what I didn't like was that I was rushed in the last [activity]." Other students explicitly commented on the timeframe, stating that they did not like "bow short it [each session] was."

In the Bridge Design project, some students explicitly stated their views on research, "I just think there is a breaking point of too much research" and "If you don't include the research, it is very fun." In addition, students felt that the timing of the Bridge Design project was less than ideal because "it was right after school. ... it was hard to sit down to do the research...."

\section{Challenges in the Implementation}

\section{Insufficient Time}

Throughout the implementation, the teachers kept reflecting that the time was insufficient to finish all the planned activities. The teachers often had to cancel the recommended 10 minute break in the middle of each session to make up time for the planned activities. For example, one teacher wrote, "I believe the amount of tasks outlined in the lesson plans are still too ambitious and our group rushed through again to try and achieve all 3 challenges. The students were not given a break at all, ... let alone the recommended ten minutes of break." Similarly, another wrote: "I think our biggest challenge with the project thus far has been time. I think the amount of material we're trying to squeeze into 90 minutes is really difficult." The lack of time was also corroborated by observations from the researchers present at each session. After a few sessions, both the teachers and research team realized the issue of insufficient time. The teachers started to work on reducing some activities while keeping the learning objectives intact with the research team's help.

\section{Complex Lesson Plans}

As the curriculum was designed to weave together multiple disciplines, facilitating the sessions was challenging. The complexity of the lesson required teachers to go out of their comfort zone and sometimes to learn together with the students, which the teachers were not necessarily prepared for, or used to doing. Teachers from the Life on Mars projects pointed out this challenge, "The biggest challenge was not being familiar with the [Mindstorms EV 3] software. Next time, I would want to be able to ... learn bow to code my self. It would have helped me facilitate and support the students more effectively." One teacher approached this challenge differently, however still not from the perspective of learning together with the students, as she wrote, "I used my teaching skills to guide students through the activity. I encouraged them to 
use the resources available .... Although I didn't feel like I had much knowledge about the programming to help them, I was at least able to guide them to the correct resources so they could attempt to figure it out on their own."

The complex curriculum was also challenging for teachers facilitating the Bridge Design project. One teacher wrote, "My biggest challenge was in figuring out how the K'Nex pieces work, but luckily, I had many students who could take that on easily." Similarly, another teacher reflected, "I feel that the lesson plans are a bit complex (too many activities, too many readings) to accomplish during the allotted time, students and teachers feel rushed."

\section{Students' Low Interest in Research}

The low interest in research largely manifested in the first several weeks when the curriculum focused on the necessary background knowledge for solving problems later on. That was when students did not have many opportunities for hands-on activities. In the Bridge Design project, one teacher reflected at the end of the third week, "I do feel like the students are starting to feel like this is not what they signed up for. I think they thought that there would be much more building involved (hands-on activities) and not so much reading and writing." Similarly, another teacher reported, "I have a hard time motivating my students to read and write [taking notes for discussions] when they just spent an entire school day doing that. While we realize that this is essential, this amount of reading and note taking may be a better format for an engineering class during school hours, rather than an after school program." The same challenge appeared in the Life on Mars project:

I gave them [the students] a choice of presentation materials to generate more interest, I tried questioning them as they worked and presented to see if they could clarify concepts... we did talk about being a critical reader and I showed them how to use the illustrations and headings on the websites to quickly find the information that they needed. Some of them were quite overwhelmed with the amount of information they needed to read through.

\section{DISCUSSION}

The hands-on activities in both projects focused on learning and applying CT, and learning STEM content as well as solving problems. For example, students learned about earthquakes, the engineering aspect of bridge design, and then designed earthquake resistant bridges based on the STEM knowledge acquired in the Bridge Design project. Similarly, students applied measurement skills (e.g., of angles, rotations, distance, and time) to program their robots in the Life on Mars project. One student summarized this succinctly when asked what he learned from his participation, “... I learned that, I didn't know that you had to incorporate math and, uh, science and engineering. I thought it would be just building the bridge."

The curriculum inquiry was also supported by technology and tools. As technology-supported learning can enable students to engage in scientific practices, when students use the tools, technology, and computational techniques that real scientists use, students engage in career exploration and preparation. The design and development of a STEM+CT curriculum paves the way for future research on what CT looks like within and across disciplines, which is critical for CT integration in K-12 classrooms.

Finally, the implementation involved multiple stakeholders from higher education, the school district and schools, and community centers, which helped "build a broad base of leadership and ownership" to amass all necessary and resources (Stanton et al., 2017, p. 5); the involvement of multiple stakeholders also leads to longterm sustainability of CT integration across K-12 education.

Overall, the teachers in both projects had positive reactions to the curriculum and viewed their experience facilitating the curriculum as highly beneficial despite of some challenges presented herein regarding the design and implementation of such a complex curriculum. The students interviewed also reacted positively to the curriculum and expressed their desire to participate in a similar project in the future. Data analysis regarding the effectiveness of the curriculum in terms of students' learning of CT and STEM knowledge is ongoing.

\section{CONCLUSIONS}

\section{Lessons Learned}

As the curriculum design team (research team) was present at both implementation sites, they saw first-hand the challenges in implementing the curriculum. To overcome the time issue and ensure a relatively relaxing environment for both teachers and students, the researchers focused on the essential readings and materials for providing necessary knowledge while revising the curriculum following the first around of implementation. The overall structure of the curriculum (such as learning objectives and time frame) remained the same. During the 
revisions, some learning activities were fine-tuned and efforts to reduce reading materials and increase more handson activities were sought.

The research team also specifically allocated time for team building and icebreaking as well as time to introduce the overall guiding question for each project at the beginning of the revised curriculum. This helped ensure that the students and teachers would have the time to get to know each other and have an overall picture of the project before working with each other, regardless of the facilitator. The introduction of the project and the overall guiding question is very important to provide the background to students so that they would be motivated to do the necessary reading and research, rather than only wanting to do the activities.

For students' low interest in reading and research, in addition to the up-front introduction of the overall guiding question, the researchers also provided more videos and replaced some text materials with videos or graphics in both projects. While working with the teachers during the implementation, the researchers became more conscientious about making the curriculum materials "kid friendly" (e.g., more visuals) and more aligned to students' reading levels.

To help the teachers better lead such a complex curriculum/lesson plans, the research team made it clear that teachers were not expected to be subject experts; instead they could and should assume the various roles of learners, facilitators, or learners. Teachers were also encouraged to use materials outside of the curriculum to help students solve the guiding question. The research team also added specific questions for research and inquiry activities in different sessions so the learning objectives could be more focused on CT.

The research team also learned that it was really beneficial to be present during the implementation to provide timely assistance for the teachers and students. However, access to the research team and content experts would not be scalable. To help transfer and maintain the presence of content experts during the curriculum implementation in other settings, the researchers have added facilitation prompts/questions in hands-on activities provided by the experts during the curriculum revisions. The additional facilitation questions/prompts were intended to help teachers better facilitate hands-on activities while students were exploring and solving various problems.

\section{Communicating CT: The Problem-Solving Process Chart}

One critical lesson the research team learned was that it was necessary to explain and communicate what CT was to teachers so that they could better facilitate the integration of CT in STEM learning. In revising the curriculum, the researchers created a problem-solving process (PSP) chart mapped with CT components (Figure 4) and included it as part of the curriculum (Yang et al., 2018). The PSP chart was based on the K-12 engineering design processes of identifying and researching problems, developing and selecting solutions, building prototypes, testing, evaluating and redesigning the solutions as needed (Chabalengula \& Mumba, 2017). The PSP chart helped the researchers communicate with the teachers, and relate CT to the problem-solving processes for practice so that teachers shared the same understanding of CT and its affordance in STEM learning. Specifically, the PSP chart would serve three purposes: 1) helping researchers share common ideas on what CT was among

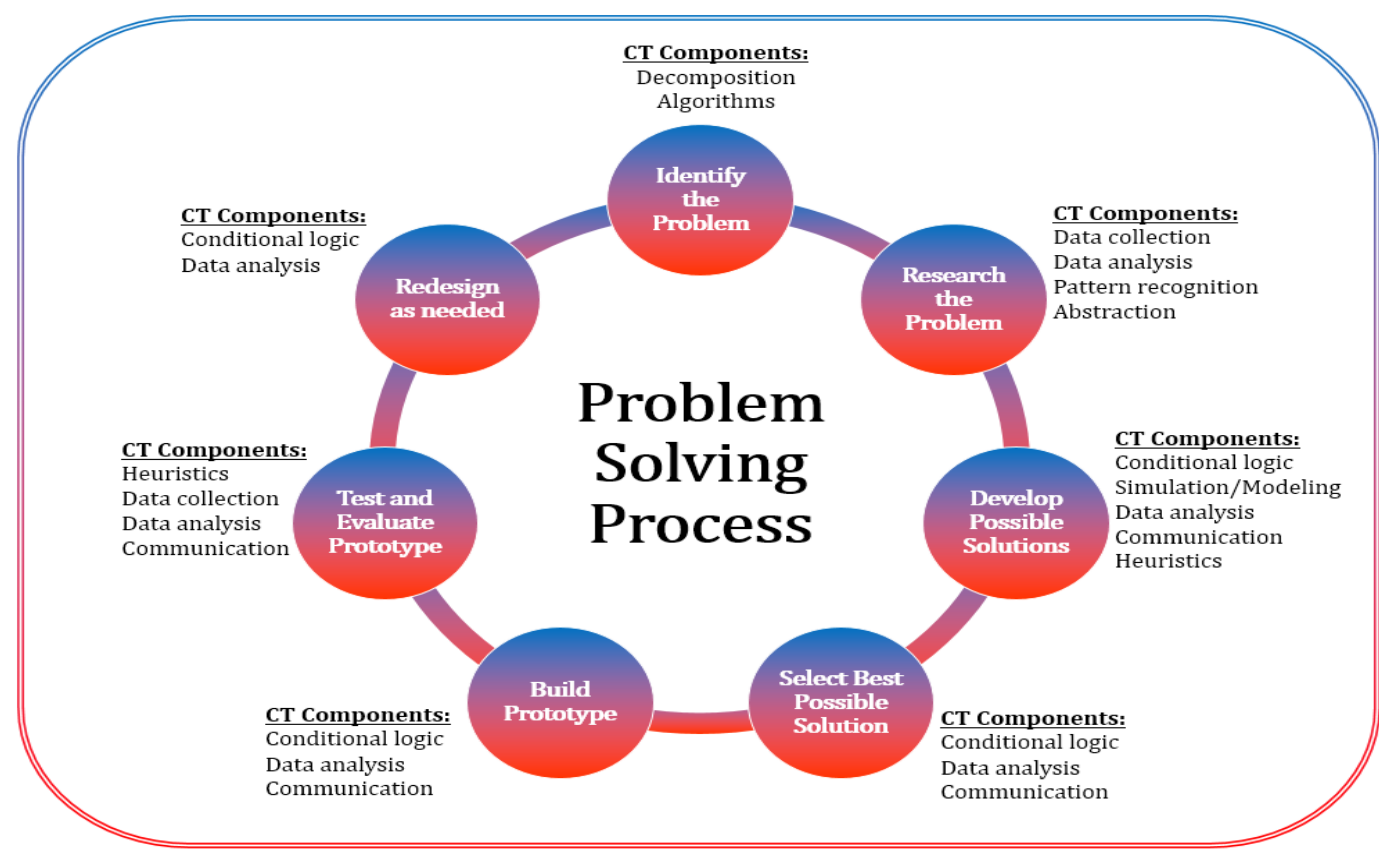

Figure 4. The PSP chart

(C) 2021 by Author/s 
themselves and with teachers; 2) helping teachers understand what CT was and how to explain CT to students; and 3) providing a means for students to reflect and recognize what CT applications and practice were in learning the STEM content and solving problems.

In Figure 3, 10 CT components, such as decomposition, abstraction and conditional logic that focus on forming and solving problems, were mapped on to one or more engineering design processes based on engineering practice and engineering design thinking (NRC, 2010). However, it should be pointed out that the mapping of one CT component on to a specific engineering design process does not mean that this CT will not be used in other processes. From our observations and preliminary findings (Yang et al., 2018), the manifestation of CT practices is very much dependent on the specific tasks at hand. During the implementation, the teachers would pull out the chart and direct students to talk about and discuss what they had learned and practiced by referring to it at the end of each session. The following screen capture shows the guiding questions the teachers used to help students reflect on their learning in the revised curriculum (Figure 5).

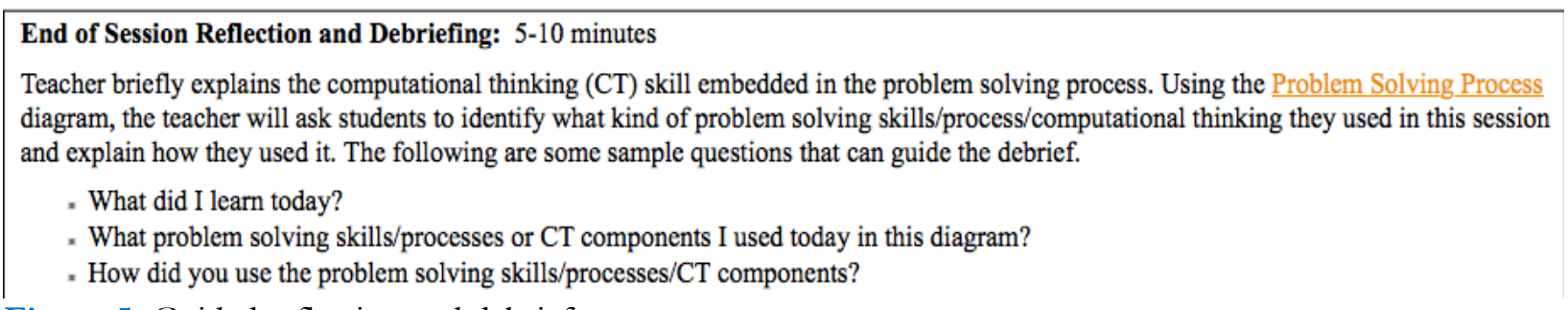

Figure 5. Guided reflection and debrief

For K-12 students to develop CT literacy, they had to learn to use CT and recognize the applications of CT across disciplinary domains, which the PSP chart could serve as a tool helping achieve this purpose.

This paper contributes to the design and development of CT-rich STEM programs for K-12 students and the effort to develop CT in students in terms of "positioning CT in the curriculum" (Voogt, et al., 2015, p. 722). Specifically, it provides a curricular example for integrating CT in cross-disciplinary practices. The integrated approach could also help make CT integration in K-12 classrooms and STEM curriculum more sustainable by learning and covering several content areas and standards simultaneously. The paper also contributes to teacher training and PD for CT integration involving various stakeholders.

However, there are some limitations associated primarily with the context of the study. First, the findings and lessons learned resulted from an informal context in a community centers' after-school program and may not apply to formal classroom settings. Second, the lessons learned involved various stakeholders (teachers, students, researchers, and community partners) which all impacted the findings, and thus they may not be able to inform other programs that involve different stakeholders. That being said, the researchers speculate that similar challenges could persist in formal settings and time would always be an issue, as well as the teachers' challenges in facilitating such a complex curriculum. Third, different or additional coding categories might emerge in the data analysis if the diversity in study contexts were increased. Therefore, additional research regarding the design and implementation of a STEM+CT curriculum in different contexts of study and participants is needed. Future research on what CT and computational practices may look like in different areas of STEM professional practice for K-12 students is recommended. Studies on how technology and tools can support the application of CT and development of CT in students, as well as research on evolving approaches to assessing CT are highly recommended.

\section{REFERENCES}

An, S., \& Lee, Y. (2014). Development of pre-service teacher education program for computational thinking. In Society for Information Technology \& Teacher Education International Conference (pp. 2055-2059). Chesapeake, VA.

Astrachan, O., \& Briggs, A. (2012). The CS principles project. ACM Inroads, 3, 38-42. https://doi.org/10.1145/2189835.2189849

Bicer, A., Boedeker, P., Capraro, R. M., \& Capraro, M. M. (2015). The effects of STEM PBL on students' mathematical and scientific vocabulary knowledge. International Journal of Contemporary Educational Research, 2, 6975. https:// files.eric.ed.gov/fulltext/ED573146.pdf

Braun, V., \& Clarke, V. (2006). Using thematic analysis in psychology. Qualitative Research in Psychology, 3, 77-101. https://doi.org/10.1191/1478088706qp063oa

Braund, M., \& Reiss, M. (2006). Towards a more authentic science curriculum: The contribution of out-of-school learning. International journal of science education, 28, 1373-1388. https:// doi.org/10.1080/09500690500498419

Brennan, K., \& Resnick, M. (2012). New frameworks for studying and assessing the development of computational thinking. In American Educational Research Association meeting. Vancouver, BC, Canada. 
Buck Institute for Education [BIE] (2017). Why project based learning? Buck Institute for Education. http://bie.org/

Catlin, D., \& Woollard, J. (2014). Educational robots and computational thinking. In Proceedings of 4th International Workshop Teaching Robotics, Teaching with Robotics \& 5 th International Conference Robotics in Education (pp. 144-151). Padova, Italy.

Chabalengula, V. M., \& Mumba, F. (2017). Engineering design skills coverage in K-12 engineering program curriculum materials in the USA. International Journal of Science Education, 39, 2209-2225. https://doi.org/10.1080/09500693.2017.1367862

Chowdhury, B., Bart, A. C., \& Kafura, D. (2018). Analysis of collaborative learning in a computational thinking class. In SIGCSE' 2018 Proceedings of the 49th ACM Technical Symposium on Computer Science Education (pp. 143148). Baltimore, Maryland, USA. https://doi.org/10.1145/3159450.3159470

Computer Science Teachers Association [CSTA] (2009). Computational thinking across the curriculum.

Czerkawski, B., \& Hernandez, J. (2012) Formal, non-formal, informal E- Learning experiences with emerging technologies: A case study of a graduate educational technology program. In Yang, H. \& Wang, Y. (Ed). Cases on formal, non-formal, and informal learning: Opportunities and practices. Hershey, PA: IGI Global. https://doi.org/10.4018/978-1-4666-1930-2.ch018

Dwyer, C., Hogan, M., \& Stewart, I. (2014). An integrated critical thinking framework for the 21st century. Thinking Skills and Creativity, 12, 43-52. https://doi.org/10.1016/j.tsc.2013.12.004

Elby, A., Gupta, A., \& Yadav, A. (2015). Research on practice using STEM inquiry embedded with computational thinking in elementary school. National Science Foundation. https://www.nsf.gov/awardsearch/showAward?AWD_ID= 1543061

Eshach, H. (2007). Bridging in-school and out-of-school learning: Formal, non-formal, and informal education. Journal of science education and technology, 16(2), 171-190. http://doi.org/10.1007/s10956-006-9027-1

Fallik, O., Rosenfeld, S., \& Eylon, B. S. (2013). School and out-of-school science: A model for bridging the gap. Studies in Science Education, 49(1), 69-91. https:// doi.org/10.1080/03057267.2013.822166

Fessakis, G., Gouli, E., \& Mavroudi, E. (2013). Problem solving by 5-6 years old kindergarten children in a computer programming environment: A case study. Computers \& Education, 63, 87-97. https://doi.org/10.1016/j.compedu.2012.11.016

Graham, M., Milanowski, A., \& Miller, J. (2012). Measuring and promoting inter-rater agreement of teacher and principal performance ratings. Center for Educator Compensation Reform. https://files.eric.ed.gov/fulltext/ ED532068.pdf

Grover, S., \& Pea, R. (2013). Computational thinking in K-12: A review of the state of the field. Educational Researcher, 42, 38-43. https://doi.org/10.3102/0013189X12463051

Grover, S., \& Pea, R. (2018). Computational thinking: A competency whose time has come. In S. Sentance, E. Barendsen, \& C. Schulte (Eds.), Computer science education: Perspectives on teacbing and learning (pp. 19-38). Bloomsbury Academic.

Inhelder, B., \& Piaget, J. (1958). The growth of logical thinking: From childhood to adolescence. Basic Books, Inc. https://doi.org/10.1037/10034-000

Israel, M., Wherfel, Q. M., Pearson, J., Shehab, S., \& Tapia, T. (2015). Empowering K-12 students with disabilities to learn computational thinking and computer programming. TEACHING Exceptional Children, 48, 45-53. https://doi.org/10.1177/0040059915594790

Lee, I., Martin, F., Denner, J., Coulter, B., Allan, W., Erickson, J., ... Werner, L. (2011). Computational thinking for youth in practice. Acm Inroads, 2, 32-37. https:/ / doi.org/10.1145/1929887.1929902

Linn, M. C., \& Hsi, S. (2000). Computers, teachers, peers: Science learning partners. Lawrence Erlbaum Associates. https://doi.org/10.4324/9781410605917

Lye, S. Y., \& Koh, J. H. L. (2014). Review on teaching and learning of computational thinking through programming: What is next for K-12? Computers in Human Behavior, 41, 51-61. https://doi.org/10.1016/j.chb.2014.09.012

Mannila, L., Settle, A., Dagiene, V., Demo, B., Grgurina, N., Mirolo, C., \& Rolandsson, L. (2014). Computational thinking in K-9 education. ITiCSE-WGR 2014: Proceedings of Working Group Reports of the 2014 Innovation and Technology in Computer Science Education Conference, 1-29. https:// doi.org/10.1145/2713609.2713610

Marx, R. W., Blumenfeld, P. C., Krajcik, J. S., \& Soloway, E. (1997). Enacting project-based science. The Elementary School Journal, 97(4), 341-358. https:// doi.org/10.1086/461870

National Research Council [NRC]. (2005). How students learn: History, science, and mathematics in the classroom. Washington, DC: The National Academies Press. https://doi.org/10.17226/10126

National Research Council. (2010). Report of a workshop on the scope and nature of computational thinking. Washington, DC: The National Academies Press. https://doi.org/10.17226/12840

National Research Council. (2011). Report of a workshop of pedagogical aspects of computational tbinking. Washington, DC: The National Academies Press. https://doi.org/10.17226/13170 
National Science Board. (2010). Preparing the next generation of STEM innovators: Identifying and developing our nation's buman capital. National Science Foundation. https://www.nsf.gov/nsb/publications/2010/nsb1033.pdf

Next Generation Science Standards (NGSS) Lead States. (2013). Next generation science standards: For states, by states. Washington, DC: The National Academies Press. https://doi.org/10.17226/18290

President's Information Technology Advisory Committee [PITAC] (2005). Computational science: Ensuring America's competitiveness. Washington, DC.

President's Council of Advisors on Science and Technology [PCAST] (2010). Prepare and inspire: K-12 education in science, technology, engineering, and math (STEM) for America's future. Washington, DC: White House Office of Science and Technology Policy (OSTP).

Sengupta, P., Dickes, A., \& Farris, A. (2018). Toward a phenomenology of computational thinking in STEM education. In M. S. Khine (Ed.), Computational thinking in STEM discipline: Foundations and research highlights (pp. 49-72). Springer. https:// doi.org/10.1007/978-3-319-93566-9_4

Sengupta, P., Kinnebrew, J. S., Basu, S., Biswas, G., \& Clark, D. (2013). Integrating computational thinking with K-12 science education using agent-based computation: A theoretical framework. Education and Information Technologies, 18, 351-380. https://doi.org/10.1007/s10639-012-9240-x

Stanton, J., Goldsmith, L., Adrion, R., Dunton, S., Hendrickson, K., Peterfreund, A., ... Zinth, J. (2017). State of the states landscape report: State-level policies supporting equitable $K-12$ computer science education. Educational Development Center. https://www.edc.org/state-states-landscape-report-state-level-policies-supportingequitable-k-12-computer-science

Stocklmayer, S. M., Rennie, L. J. \& Gilbert, J. K. (2010). The roles of the formal and informal sectors in the provision of effective science education. Studies in Science Education, 46(1), 1-44. https://doi.org/10.1080/03057260903562284

Voogt, J., Fisser, P., Good, J., Mishra, P. \& Yadav, A. (2015). Computational thinking in compulsory education: Towards an agenda for research and practice. Education and Information Technologies, 20, 715-728. https://doi.org/10.1007/s10639-015-9412-6

Wang, H.-H., Moore, T. J., Roehrig, G. H., \& Park, M. S. (2011). STEM integration: Teacher perceptions and practice. Journal of Pre-College Engineering Education, 1, 1-13. https:// doi.org/10.5703/1288284314636

Wilkerson, M. H., \& Fenwich, M. (2016). Using mathematics and computational thinking. In C. V. Schwarz, C. Passmore, \& B. J. Reiser (Eds.), Helping students make sense of the world using next generation science and engineering practices (pp. 181-204). Arlington, VA: National Science Teachers’ Association Press.

Wing, J. (2008). Computational thinking and thinking about computing. Philosophical Transactions. Series A, Mathematical, Physical, and Engineering Sciences, 366, 3717-3725. https://doi.org/10.1098/rsta.2008.0118

Wing, J. M. (2006). Computational thinking. Communications of the ACM, 49, 33-35. https:// doi.org/10.1145/1118178.1118215

Yadav, A., Zhou, N., Mayfield, C., Hambrusch, S., \& Korb, J. T. (2011). Introducing computational thinking in education courses. In Proceedings of the 42nd ACM Technical Symposium on Computer Science Education (pp. 465-470). Dallas, Texas, USA. https://doi.org/10.1145/1953163.1953297

Yang, D., Chittoori, B., Baek, Y., \& Stewart, W. (2019). Elementary students' computational thinking practice in a bridge design and building challenge (Fundamental). Proceedings of 2019 American Society for Engineering Education (ASEE) Annual Conference and Exposition, Tampa, FL.

Yang, D., Swanson, S., Chittoori, B. \& Baek, Y. (2018). Work-in-Progress: Integrating computational thinking in STEM education through a project-based learning approach. Proceedings of 2018 American Society for Engineering Education (ASEE) Annual Conference and Exposition, Salt Lake City, UH. 